TITLE:

\title{
Total Synthesis of (-)-Sigillin A: A Polychlorinated and Polyoxygenated Natural Product
}

\section{$\operatorname{AUTHOR}(\mathrm{S}):$}

Yamaoka, Yousuke; Nakayama, Takamori; Kawai, Shota; Takasu, Kiyosei

\section{CITATION:}

Yamaoka, Yousuke ...[et al]. Total Synthesis of (-)-Sigillin A: A Polychlorinated and Polyoxygenated Natural Product. Organic Letters 2020, 22(19): 7721-7724

\section{ISSUE DATE:}

2020-10-02

URL:

http://hdl.handle.net/2433/255627

\section{RIGHT:}

This document is the Accepted Manuscript version of a Published Work that appeared in final form in Organic Letters, copyright $\odot$ American Chemical Society after peer review and technical editing by the publisher. To access the final edited and published work see https://doi.org/10.1021/acs.orglett.0c02930.; The full-text file will be made open to the public on 16 September 2021 in accordance with publisher's 'Terms and Conditions for Self-Archiving'., この論文は出版 社版でありません。引用の際には出版社版をご確認ざ利用ください。; This is not the published version. Please cite only the published version. 


\title{
Total Synthesis of (-)-Sigillin A: A Poly-Chlorinated and Poly-Oxy- genated Natural Product
}

\author{
Yousuke Yamaoka,* Takamori Nakayama, Shota Kawai, and Kiyosei Takasu* \\ Graduate School of Pharmaceutical Sciences, Kyoto University, Yoshida, Sakyo-ku, Kyoto 606-8501, Japan \\ Supporting Information Placeholder
}

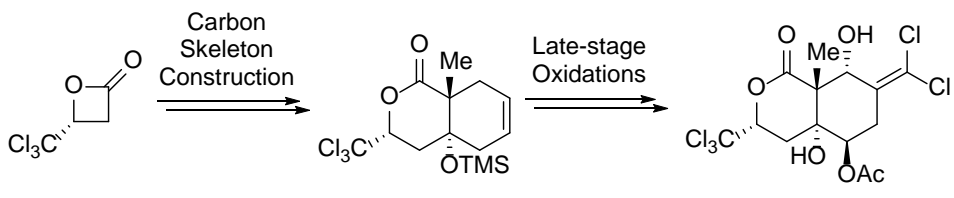

sigillin A

\begin{abstract}
The total synthesis of (-)-sigillin A, a highly chlorinated and oxygenated octahydroisocoumarin, is described herein. A hexahydroisocoumarin skeleton was constructed from $(R)$-4-(trichloromethyl)oxetan-2-one in seven steps. Its unique manganese oxidation provided an enone as the key intermediate of sigillin A. Stereoselective installation of two hydroxy groups and formation of gem-dichloroalkene from the corresponding ketone led to the total synthesis of (-)-sigillin A in a total of 16 steps.
\end{abstract}

Halogenated compounds are often used in the pharmaceutical and agricultural industries. ${ }^{1}$ Approximately $40 \%$ of the drugs that are a part of the market or used in clinical trials are halogenated compounds; this is because incorporation of halogen atoms into drug candidates improves the metabolic stability, the lipophilicity, and the drug target affinity. ${ }^{2}$ Recently the number of reports on halogenated natural products has been increased owing to the development of isolation and identification technologies. ${ }^{3,4}$ Thus, efficient syntheses of newly isolated halogenated products would be attractive for the development of various areas of chemistry such as drug discovery.

Sigillin A (1) and its congeners 2-9 are polychlorinated octahydroisocoumarins that have been isolated previously from the snow flea Ceratophysella sigillata (Collembola) in 2015 by Schulz's group (Figure 1). ${ }^{5}$ The structure and the absolute configuration of $\mathbf{1}$ was revealed by X-ray crystallographic analysis. Sigillins have characteristic structural features in these rather compact skeletons: 1 possesses five chlorine atoms and three hydroxy groups in four consecutive stereocenters decorated in a trans-fused octahydroisocoumarin structure. This molecule has showed high repellent activity in a bioassay against predatory ant Myrmica rubra and some cell toxicity. We have been fascinated by these structural features and biological activities, which has led us to investigate the total synthesis of this molecule.

Total synthesis of $\mathbf{1}$ and related natural products have not been accomplished to date. Schulz's group reported the synthesis of desoxysigillin A, which lacks hydroxy groups at the C-5 and C-6 positions (Scheme 1). ${ }^{5,} 6$ They found that the installation of a gem-dichloroalkene moiety, one of the unique functional groups of $\mathbf{1}$, is quite challenging and gives the desired compound 11 with only $2 \%$ yield. Thus, the major challenge in the synthesis of this natural product is the introduction of these hydroxy groups and gem-dichloroalkene group.

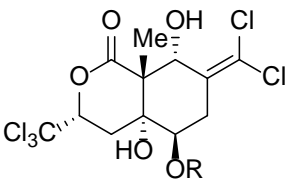

$$
\begin{aligned}
& R=A c: \text { Sigillin A (1) } \\
& R=H: \text { Sigillin B (2) }
\end{aligned}
$$<smiles>[R20]C1CC(C(Cl)(Cl)Cl)CC2(O)C(=O)O[C@@H](C(Cl)(Cl)Cl)C[C@@]12O</smiles>

$R=A c:$ Sigillin $E(5)$ $\mathrm{R}=\mathrm{H}$ : Sigillin $\mathrm{F}(\mathbf{6})$<smiles>CC(=O)OC1CC(=C(Cl)Cl)C(O)C2(O)C(=O)OC(=C(Cl)Cl)CC12O</smiles>

Figure 1. Structure of Sigillins 1-9.

Herein, we report the first asymmetric total synthesis of sigillin A. Our synthetic plan is depicted in Scheme 2. We envisioned that the synthesis of sigillin A could be accomplished by dichloromethylenation of the corresponding ketone $\mathbf{1 2}$, which would be prepared using enone $\mathbf{1 3}$ via a boron conjugate 
addition. Enone 13 would be sourced from hexahydroisocoumarin 14 by performing several oxidations. The carbon framework of sigillin 14 was expected to be constructed from the $\beta$ keto- $\delta$-valerolactone 15 via double allylations and ring-closing metathesis. Furthermore, 15 could be synthesized by Claisen condensation of the known optically active $\beta$-lactone $\mathbf{1 6}^{\mathbf{7}}$ with tert-butyl propionate, followed by lactonization.

\section{Scheme 1. Synthesis of desoxysigillin A by Schulz ${ }^{6}$}

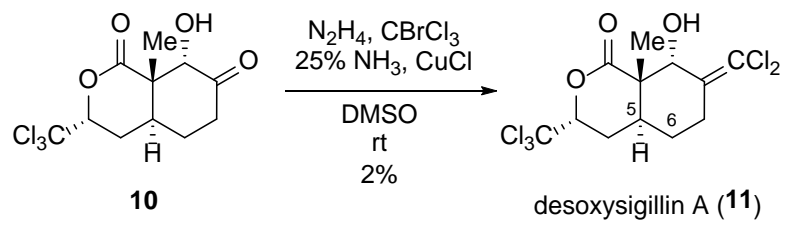

Scheme 2. Our synthetic plan

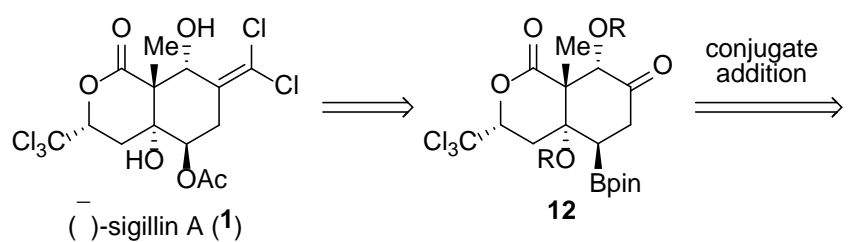

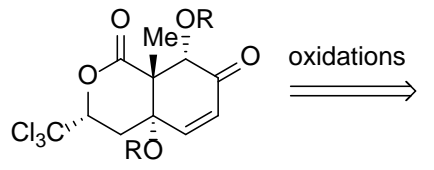

13<smiles>CC1=C(O)C[C@@H](C(Cl)(Cl)Cl)OC1=O</smiles>

15

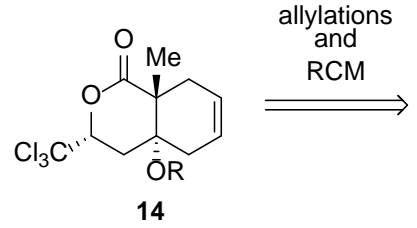

14<smiles>O=C1C[C@@H](Cl)O1</smiles>

16 (>99\% ee) (ref 8)
We initiated the synthesis of hexahydroisocoumarin 21 with the known enantiopure $\beta$-lactone 16 (Scheme 3). Claisen condensation of $\beta$-lactone $\mathbf{1 6}$ with tert-butyl propionate produced 5-hydroxy-3-oxoester 17 at a yield of $82 \%$, which was subjected to cyclization under acidic conditions to afford the $\beta$ keto- $\delta$-valerolactone 15 (fragment of sigillin A on the left). Next, we performed the electrophilic allylation of keto-lactone 15. Tsuji-Trost allylation ${ }^{8 a}$ of $\mathbf{1 5}$ using allyl acetate produced the desired compound 19 in $70 \%$ yield albeit with low diastereoselectivity ( $d r=60: 40)$. Even the use of chiral ligands, such as $\mathrm{PHOX}^{8 \mathrm{~b}}$ and the Trost ligand ${ }^{8 \mathrm{c}}$ could not improve the diastereoselectivity. We turned our attention to the intramolecular variant of this reaction, referred to in Mulzer's protocol, ${ }^{9}$ to improve the diastereoselectivity. The allyl carbonate $\mathbf{1 8}$ could be prepared from 15 using allyl chloroformate in an almost quantitative yield. As expected, allylation of $\mathbf{1 8}$ catalyzed by 3 mol \% of $\mathrm{Pd}_{2} \mathrm{dba}_{3} \cdot \mathrm{CHCl}_{3}$ with $15 \mathrm{~mol} \%$ of $\mathrm{PPh}_{3}$ as a ligand proceeded even at $-78{ }^{\circ} \mathrm{C}$ to obtain 19 and showed good diastereoselectivity $(\mathrm{dr}=85: 15)$ and high yield $(90 \%) .{ }^{10}$ After screening several phosphine ligands, (2-furyl) ${ }_{3} \mathrm{P}$ was found to be suitable ( $d r=94: 6)$. Furthermore, the amount of catalyst loading could be reduced to $1 \mathrm{~mol} \%$ of the palladium source without any loss in yield and diastereoselectivity $(\mathrm{dr}=94: 6)$. Nucleophilic allylation of $19(\mathrm{dr}=94: 6)$ with allylzinc bromide ${ }^{11}$ led to the production of alcohol 20 with a $95 \%$ yield that exhibited high diastereoselectivity $(\mathrm{dr}=94: 6)$. The crude was directly purified by recrystallization to produce $\mathbf{2 0}$ in $78 \%$ yield as a single stereoisomer, whose structure was confirmed by Xray crystallography. Then, $\mathbf{2 0}$ was subject to ring-closing metathesis and silyl protection to achieve the synthesis of compound 21 on a $>5$ gram scale. Thus, we successfully constructed a carbon framework of sigillin A from the known $(R)$-4-trichloromethyl-2-oxetanone in 7 steps.

\section{Scheme 3. Construction of the Carbon Skeleton of Sigillin A}

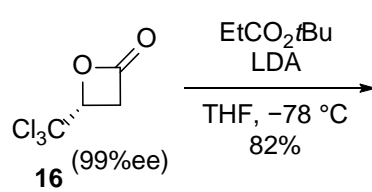<smiles>CCCCC(=O)C(C)C(=O)C[C@@H](O)C(Cl)(Cl)Cl</smiles>

17<smiles>C=CC[C@]1(C)C(=O)C[C@@H](C(Cl)(Cl)Cl)OC1=O</smiles>

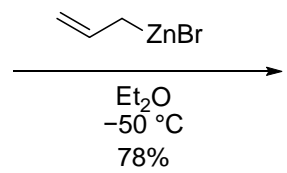

(after recystallization)

PTSA

$\underset{\text { toluene }}{\stackrel{(30 \mathrm{~mol} \%)}{\longrightarrow}}$

$70{ }^{\circ} \mathrm{C}$

$78 \%$

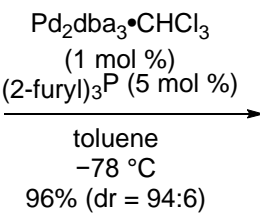

$\mathrm{Pd}_{2} \mathrm{dba}_{3} \cdot \mathrm{CHCl}_{3}$ (1 $\mathrm{mol} \%$

$-78^{\circ} \mathrm{C}$

$96 \%(d r=94: 6)$

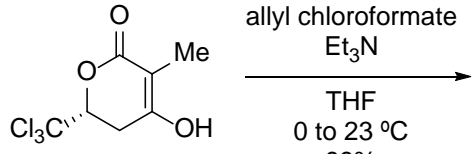

15
99\%

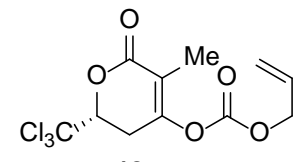

18 
Scheme 4. Oxidative Stage toward the Synthesis of Sigillin $A^{a}$

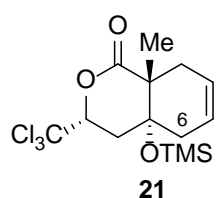

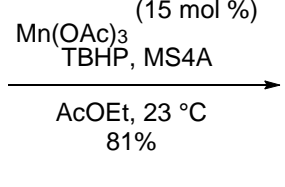

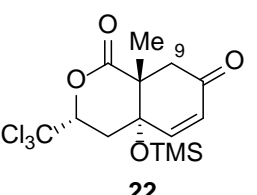

$\ominus_{\mathrm{Cy}}^{\mathrm{BF}_{4}} \oplus \sqrt{\mathrm{N}_{-C y}}$

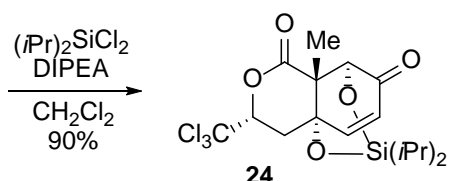

24

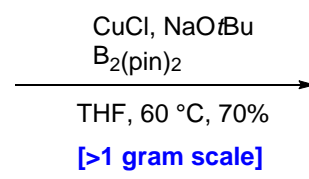

[ $>1$ gram scale]

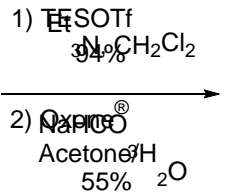

$55 \% \quad 2 \mathrm{O}$

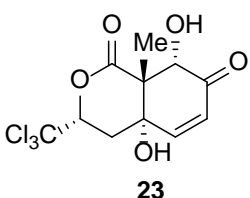

23

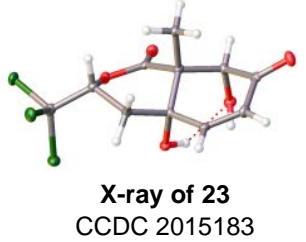

CCDC 2015183

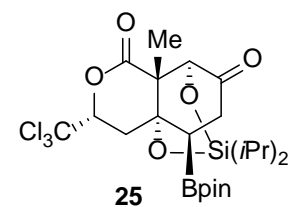

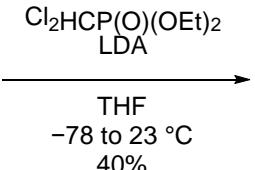

$40 \%$

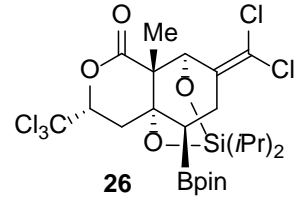

26

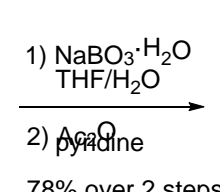

$78 \%$ over 2 steps

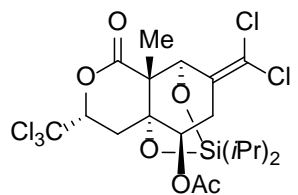

27

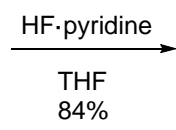

$4 \%$

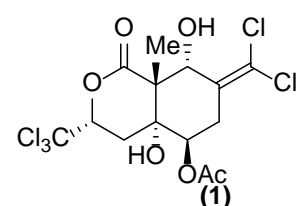

sigillin $A$

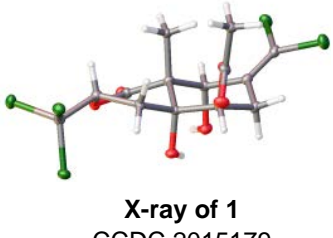

CCDC 2015179

${ }^{a}$ ORTEP view of compounds $\mathbf{2 3}$ and $\mathbf{1}$ with thermal ellipsoids drawn at the $80 \%$ probability level.

To increase the oxidation level toward sigillin A appropriately, several oxidation reactions were attempted. First, we examined the allylic oxidation of $\mathbf{2 1}$ to introduce an oxygen functionality at $\mathrm{C}-6$ position. The use of $\mathrm{SeO}_{2}, \mathrm{Pd}(\mathrm{OAc})_{2} / \mathrm{BQ}$ and $\mathrm{CrO}_{3}$ resulted in the formation of complex mixtures. After tremendous effort of oxidations, we found that $\mathrm{Mn}(\mathrm{OAc})_{3}$-catalyzed allylic oxidation ${ }^{12 a}$ of $\mathbf{2 1}$ proceeded with unexpected regioselectivity to afford enone 22 in high yield (Scheme 4). We assumed that this regioselectivity arose from the bulkiness of silyl group. Initially, the hydrogen atom at C-6 position might be abstracted by the peroxy radical. After the generated allyl radical was delocalized, oxidation would occur at the less hindered position to produce enone $22 .{ }^{12 b}$ Then, enone 22 was employed in the installation of a hydroxy group at the C-9 position. In situ Rubottom oxidation ${ }^{13}$ of triethylsiloxy diene using DMDO led to successful installation of a hydroxy group with the desired configuration to afford diol $\mathbf{2 3}$ as a single diastereomer. ${ }^{14}$ The unpredicted diol $\mathbf{2 3}$ was obtained as a result of the loss of TMS protecting group of the tertiary hydroxy group. The structure of $\mathbf{2 3}$ was confirmed by X-ray crystallographic analysis. We speculated that TMS group might translocate to the secondary hydroxy group and then be removed under aqueous basic conditions. Protection of diol 23 with dichlorodialkylsilane led to the production of the bridged silyl protected compound 24. For installation of a hydroxy group at the C-6 position, copper-promoted conjugate addition ${ }^{15}$ of a boron pinacol ester to enone $\mathbf{2 4}$ gave the desired product $\mathbf{2 5}$ as a single diastereomer. Boron would attack enone $\mathbf{2 4}$ to avoid the steric hindrance of the bulky diisopropylsilyl group. As mentioned in the previous report, ${ }^{5,6}$ transformation of carbonyl group into dichloroalkene proved to be problematic for us. Several methods for the formation of dichloroalkene from ketone are reported. ${ }^{16}$ The most reliable methods using Wittig-type reactions with spe- cies such as the $\mathrm{CCl}_{4} /$ phosphine system ${ }^{17}$ did not lead to a reaction with 25, and the reactions were complicated in more forcing conditions such as refluxing or under microwave-assisted conditions. $\beta$-Elimination-based reactions ${ }^{18}$ have also been investigated. However, the formation of trichloromethyl carbinol using 25 with $\mathrm{LiCCl}_{3}$ has remained unsuccessful. To our delight, the transformation was achieved using Wittig-Horner reactant ${ }^{19}$ $\left(\mathrm{EtO}_{2}\right) \mathrm{P}(\mathrm{O}) \mathrm{CCl}_{2} \mathrm{Li}$ to produce dichloroalkene 26 in $40 \%$ yield. The key to success was that the corresponding carbanion was more nucleophilic than the Wittig-type phosphonium ylide ${ }^{20}$ and less reactive than carbanions such as $\mathrm{LiCCl}_{3}$, which prevented side reactions. Oxidative cleavage of the $\mathrm{C}-\mathrm{B}$ bond followed by acetylation afforded 27 in $78 \%$ yield over 2 steps. Removal of the silyl group by Hf·pyridine produced sigillin A (1) in a total of 16 steps from $(R)$-4-trichloromethyl-2-oxetanone.

In summary, we accomplished the first asymmetric total synthesis of (-)-sigillin A in 16 steps by using enantiomerically pure $\beta$-lactone 16. The keys to the success of the synthesis were 1) an unexpected manganese allylic oxidation to form enone 22; 2) stereoselective installation of two hydroxy groups via Rubottom oxidation and borylation/oxidation using enone 22; 3) formation of gem-dichloroalkene $\mathbf{2 6}$ by the Wittig-Horner reaction. These late-stage oxidation strategies proved to be effective in the synthesis of sigillin A. The syntheses and biological evaluation of related analogues of sigillin A are currently under way.

\section{Supporting Information}

The Supporting Information is available free of charge on the ACS Publications website.

Experiment procedures, Supplemental figure, Copies of ${ }^{1} \mathrm{H}$ and ${ }^{13} \mathrm{C}$ NMR spectra (PDF) 
Crystallographic information for $\mathbf{2 0}$ (CIF)

Crystallographic information for 23 (CIF)

Crystallographic information for $\mathbf{1}$ (CIF)

\section{AUTHOR INFORMATION}

\author{
Corresponding Author \\ * yyamaoka@pharm.kyoto-u.ac.jp \\ * kay-t@pharm.kyoto-u.ac.jp
}

\section{Notes}

The authors declare no competing financial interest.

\section{ACKNOWLEDGMENT}

This work was financially supported by JSPS KAKENHI (Grant Numbers 18K05103, 19H03350), MEXT KAKNHI (Grant Number JP16H01147) in Middle Molecular Strategy, and AMED Platform for Supporting Drug Discovery and Life Science Research (Grant Number jp19am0101092j0003). Y.Y. thanks the Takeda Science Foundation.

\section{REFERENCES}

(1) Hernandes, M. Z.; Cavalcanti, S. M. T.; Moreira, D. R. M. de Azevedo Jr, W. F.; Leite, A. C. L. Halogen Atoms in the Modern Medicinal Chemistry: Hints for the Drug Design. Curr. Drug Target 2010, 11, 303-314.

(2) Xu, Z.; Yang, Z.; Lu, Y.; Chen, K.; Zhu, W. Halogen Bond: Its Role beyond Drug-Target Binding Affinity for Drug Discovery and Development. J. Chem. Inf. Model. 2014, 54, 69-78.

(3) (a) Gribble, G. W. Naturally Occurring Organohalogen Compounds. Acc. Chem. Res. 1998, 31, 141-152. (b) Gribble, G. W. A Recent Survey of Naturally Occurring Organohalogen Compounds. Environ. Chem. 2015, 12, 396-405. (c) Gribble, G. W. Biological Activity of Recently Discovered Halogenated Marine Natural Products. Mar. Drugs. 2015, 13, 4044-4136.

(4) Zeng, J.; Zhan, J. Chlorinated Natural Products and Related Halogenases. Isr. J. Chem. 2019, 59, 387-402.

(5) Schmidt, W.; Schulze, T. M.; Brasse, G.; Nagrodzka, E.; Maczka, M.; Zettel, J.; Jones, P. G.; Grunenberg, J.; Hilker, M.; Trauer-Kizilelma, U.; Braun, U.; Schulz, S. Sigillin A, a Unique Polychlorinated Arthropod Deterrent from the Snow Flea Ceratophysella sigillata. Angew. Chem., Int. Ed. 2015, 54, 7698-7702.

(6) Steinbiss M.; Maczka, M.; Langewald, J.; London, B.; Vallinayagam, R.; Jones, P. G.; Bastiaans, H.; Schulz, S. Sigillins from Springtails Are Potent Natural Insecticides. J. Nat. Prod. 2020, 83, 468-472.

(7) Ganta, A.; Shamshina, J. L. Cafiero, L. R. Snowden, T. S. Stereoselective Synthesis of Cis- or Trans-2,4-Disubstituted Butyrolactones from Wynberg Lactone. Tetrahedron 2012, 68, 5396-5405.

(8) (a) Trost, B. M.; Crawley, M. L. Asymmetric Transition-MetalCatalyzed Allylic Alkylations: Applications in Total Synthesis. Chem. Rev. 2003, 103, 2921-2944. (b) Behenna, D. C.; Stolz, B. M. The Enantioselective Tsuji Allylation. J. Am. Chem. Soc. 2004, 126, 15044-15045. (c) Trost, B. M.; Xu, J. Regio- and Enantioselective Pd-Catalyzed Allylic Alkylation of Ketones through Allyl Enol Carbonates. J. Am. Chem. Soc. 2005, 127, 2846-2847.

(9) Prantz, K.; Mulzer, J. Synthesis of (Z)-Trisubstituted Olefins by Decarboxylative Grob-Type Fragmentations: Epothilone D, Discodermolide, and Peloruside A. Chem. Eur. J. 2010, 16, 485-506.

(10) See the Supporting Information for optimization conditions of allylation of $\mathbf{1 8 .}$
(11) McNulty, J.; McLeod, D. Total Enantioselective Synthesis of the Endophytic Fungal Polyketide Phomolide $\mathrm{H}$ and Its Structural Revision. Eur. J. Org. Chem. 2017, 29-33.

(12) (a) Shing, T. K. M.; Yeung, Y.-Y.; Su, P. L. Mild Manganese (III) Acetate Catalyzed Allylic Oxidation: Application to Simple and Complex Alkenes. Org. Lett. 2006, 8, 3149-3151. (b) Kumaran, R. S.; Mehta, G. An Enantiodivergent Protocol from $R$-(-)-Carvone: Synthesis of Dihydroagarofuran Sesquiterpenoid 1-Deacetoxy-ent-orbicuin A. Tetrahedron 2015, 71, 1547-1554.

(13) Mizuki, K.; Iwahashi, K.; Murata, N.; Ikeda, M.; Nakai, Y.; Yoneyama, H.; Harusawa, S.; Ox-3763.

(14) See the Supporting Information for optimization conditions of Rubottom oxidation of 22.

(15) (a) Li, H.; Chen, Q.; Lu, Z.; Li, A. Total Syntheses of Aflavazole and 14-Hydroxyaflavinine. J. Am. Chem. Soc. 2016, 138, 15555-15558. (b) Lee, K.-S.; Zhugralin, A. R.; Hoveyda, A. H. Efficient C-B Bond Formation Promoted by N-Heterocyclic Carbenes: Synthesis of Tertiary and Quaternary B-Substituted Carbons through Metal-Free Catalytic Boron Conjugate Additions to Cyclic and Acyclic $\alpha, \beta$-Unsaturated Carbonyls. J. Am. Chem. Soc. 2009, 131, 7253-7255. (c) Marcus, A. P.; Sarpong, R. Synthesis of the Tetracyclic Core of Tetrapetalone A Enabled by a Pyrrole Reductive Alkylation. Org. Lett. 2010, 12, 4560-4563.

(16) Chelucci, G. Synthesis and Metal-Catalyzed Reaction of gemDihalovinyl Systems. Chem. Rev. 2012, 112, 1344-1462.

(17) Burton, G.; Elder, J. S.; Fell, S. C. M.; Stachulski, A. V. Acetonitrile: An Excellent Solvent for the 1,1-Dichloromethylenation of Certain Ketones. Tetrahedron Lett. 1988, 29, 30033006.

(18) (a) Barluenga, J.; Fernández-Simón, J. L. Concellón, J. M.; Yus, M. Synthesis of Mono and gem-Dihalogeno-olefins from Carbonyl Compounds and in situ Generated Lithium Carbenoids. J. Chem. Soc., Perkin Trans. 1 1989, 691-694. (b) Aggarwal, V. K.; Mereu, A. Amidine-Promoted Addition of Chloroform to Carbonyl Compounds. J. Org. Chem. 2000, 65, 7211-7212.

(19) (a) Seyferth, D.; Marmor, R. S. Halomethyl-Metal Compounds: LXIII. Diethyl Lithiodichloromethylphosphonate and Tetraethyl Lithiochloromethylenediphosphonate. J. Organomet. Chem. 1973, 59, 237-245. (b) Savignac, P.; Petrova J.; Dreux, M.; Coutrot, P. $\alpha$-Chlorination and Carbonyl Olefination. Synthesis 1975, 535-536. (c) Mouriès, V.; Waschbüsch, R.; Carran, J.; Savignac, P. A Facile and High Yielding Synthesis of Symmetrical and Unsymmetrical Diarylalkynes Using Diethyl Dichloromethylphosphonate as Precursor. Synthesis 1998, 271274. (d) Cordes, J.; Wessel, C.; Harms, K.; Koert, U. meta-Selective Aromatic Borylation as Key Step in the Synthesis of Poipuol. Synthesis 2008, 2217-2220.

(20) Wadsworth, W. S.; Emmons, W. D. The Utility of Phosphonate Carbanions in Olefin Synthesis. J. Am. Chem. Soc. 1961, 83, 1733-1738. 